\title{
Reseña del libro coordinado por Ángel Díaz Barriga y José María García Garduño, Desarrollo del currículum en América Latina. Experiencia de diez países ${ }^{1}$
}

María-Concepción Barrón-Tirado
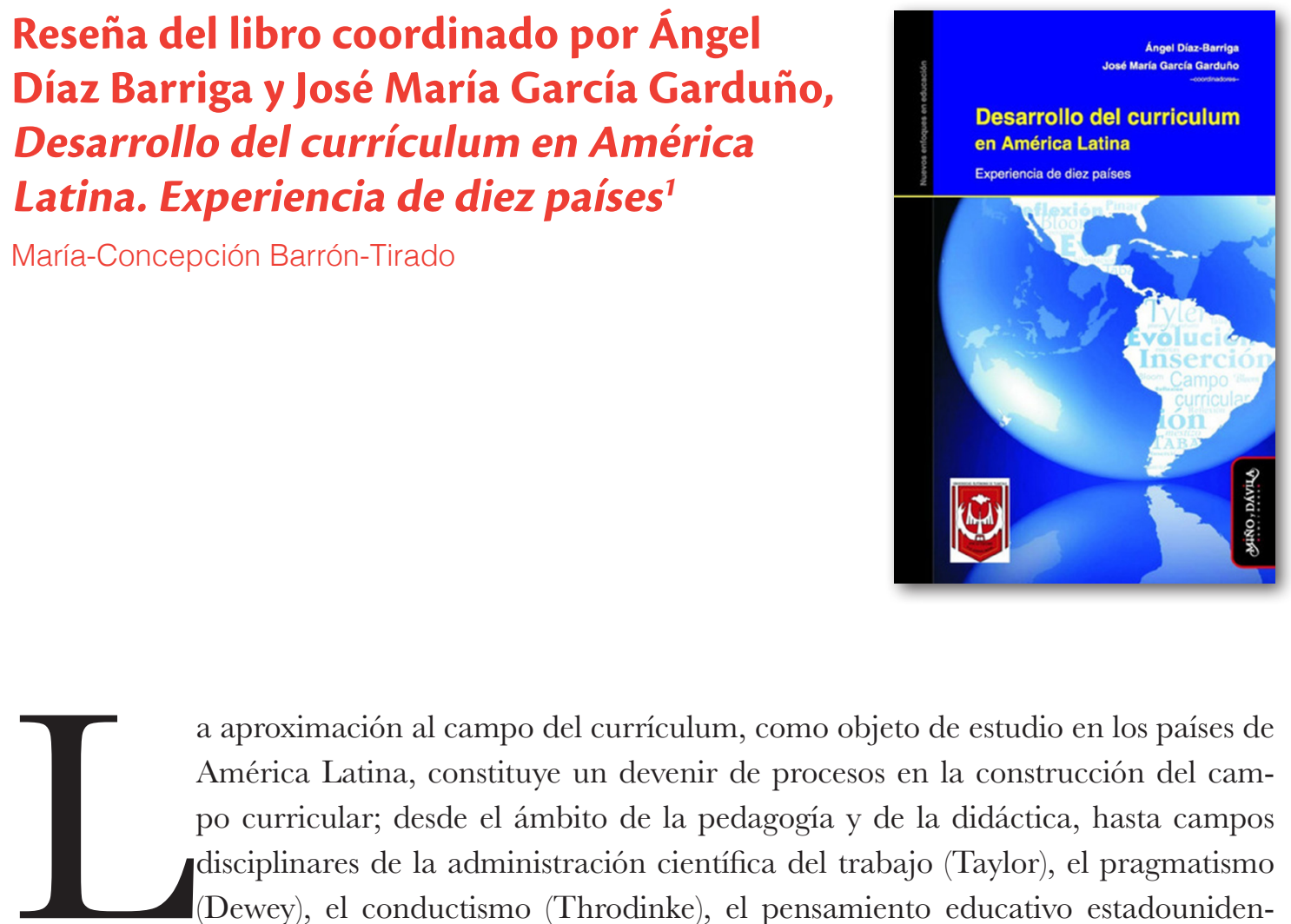

a aproximación al campo del currículum, como objeto de estudio en los países de América Latina, constituye un devenir de procesos en la construcción del campo curricular; desde el ámbito de la pedagogía y de la didáctica, hasta campos disciplinares de la administración científica del trabajo (Taylor), el pragmatismo (Dewey), el conductismo (Throdinke), el pensamiento educativo estadounidense (Tyler, Bloom, Taba), los planteamientos contestatarios latinoamericanos (Freire, Illich), así como la teoría crítica, la poscrítica y posestructural.

En la obra se pone de manifiesto que la construcción, debates, conflictos, rupturas y disrupciones en el campo del currículum en América Latina no ha sido lineal, ni progresiva, en el marco de múltiples determinaciones sociales, históricas, políticas, culturales que signan la historia de cada país y se entretejen para posicionar, desarrollar o eliminar aquellas perspectivas teóricas hegemónicas sobre el campo. Dar cuenta de ello, posibilita acercamientos con múltiples rostros y miradas, por lo que se hace necesario reconocer que "la ruptura no es un tiempo muerto e indiferenciado que se intercale - siquiera fuese por un instante- entre dos fases manifiestas; no es el lapso sin duración que separe dos épocas y desplegase de una y otra parte de una fisura, dos tiempos heterogéneos; es siempre entre unas positividades definidas, una discontinuidad especificada por cierto número de transformaciones distintas" (M. Foucault (2007), La arqueología del saber, México, Siglo XXI).

\section{María-Concepción Barrón-Tirado}

Recepción: 11/05/19. Aprobación: 15/10/20.

\footnotetext{
${ }^{1}$ Ángel Díaz Barriga y José María García Garduño (coords.) (2014), Desarrollo del currículum en América Latina. Experiencia de diez paises, Buenos Aires, Miño y Dávila/ Universidad Autónoma de Tlaxcala.
} 
La riqueza de este libro radica en presentar un mosaico de experiencias de aprendizaje desarrolladas en diez paises latinoamericanos: Argentina, Bolivia, Brasil, Colombia, Costa Rica, Chile, República Dominicana, México, Venezuela y Uruguay, a lo largo de, aproximadamente, 70 años. Dichas experiencias se caracterizan por la diversidad de condiciones políticas, culturales y educativas de cada uno de ellos, así como por los diferentes marcos epistemológicos y teóricos desde los que se aborda el currículum y sus procesos de construcción, apropiación, resistencia, adaptación y reinterpretación a partir de políticas educativas orientadas a la generación de espacios de reflexión y acción.

Las rutas seguidas por los diversos participantes para dar cuenta de la conformación del campo del currículum en sus respectivos países, muestran el entramado complejo en el que se trenzan las políticas sociales, económicas, educativas y curriculares, así como las disputas teórico-metodológicas y los diversos posicionamientos respaldados por los grupos de poder en turno.

El primer capítulo, denominado "Los estudios del currículum en Argentina: particularidades de una disputa académica", de Silvina Feeney, plantea que la reflexión sobre currículum aparece a finales de 1950 y principios de 1960, como parte del proceso de modernización del Estado y la profesionalización del campo educativo; periodo en el que la teoría curricular de corte tecnológico consigue una extraordinaria difusión (Tyler y Taba) y en el que se produce, simultáneamente, un replanteamiento de la obra de Jean Piaget.

Se señala que, para la década de los setenta e inicios de los ochenta, el ascenso de los militares al poder frena el debate curricular y la conformación del "grupo cordobés" pone en duda el paradigma tyleriano, orientando la crítica didáctica hacia una crítica política bajo la influencia de diversos autores de la Escuela de Frankfurt. Durante la represión militar, Eduardo Remedi y Alfredo Furlán abren una doble línea conceptual: el currículum como propuesta político educativa y como campo de estudio de las ciencias de la educación. Por su parte, Susana Barco introduce un diseño curricular participativo enfocado en la revisión de las prácticas docentes.

El regreso de la democracia, a partir de 1983, se tradujo en un incremento en la matrícula estudiantil y en una promoción de las pedagogías centradas en el alumno. Para la década de los noventa, con la Ley Federal de Educación, surgen una serie de reformas cuyo impacto abarcó desde la educación inicial hasta la formación docente y cuyos retos se centraron en garantizar la calidad de la enseñanza y la equidad en el acceso a la educación. Durante este periodo, la producción de conocimientos sobre educación se generó en dos contextos institucionales diversos: 1) el campo del saber científico-académico de las ciencias sociales y humanidades, donde el debate curricular era muy escaso, y 2) en el terreno de los saberes técnico-burocráticos y de las prácticas pedagógicas, donde existía una fragmentación de los saberes con relación al currículum.

En el segundo capítulo, denominado "Políticas educativas y dificultades de constitución del campo curricular en Bolivia", elaborado por Mario Yapu, se señala que el currículum como concepto aparece con la reforma educativa de 1994; anteriormente se le había sustituido por planes de estudio, programas escolares, disciplinas, etcétera. El Estado, a través de sus reformas educativas, agenda el debate curricular tanto en los espacios académicos como en la sociedad civil.

A fines del siglo XIX, la educación boliviana se centró en la libre enseñanza, la municipalización y las propuestas pedagógicas globales con el objetivo de transitar hacia un modelo nacionalista que promoviese la discusión sobre la pedagogía, la didáctica y el método de enseñanza centrado en las capacidades de las y los niños. Fue hasta principios del siglo XX que se introduce una propuesta pedagógica con fundamentos científicos, biológicos, psicológicos y sociológicos 
para promover el espíritu científico en las y los niños, hombres de acción y maestros apóstoles con valores nacionales. A partir del 1930, con las escuelas indígenas, se establece un modelo educativo que articula la escuela con la comunidad a partir de diferentes métodos basados en Decroly, Coussinet, métodos de proyectos, escuelas de trabajo, entre otros.

En 1952, con la transformación del Estado nacional y el desarrollo económico moderno, se fortalece la educación técnica y científica, centralizando la educación en torno a la nación, pero con la distinción entre educación rural (comprende tres niveles: primaria, escuelas vocacionales y técnicas, y escuelas normales rurales) y educación urbana (comprende cinco niveles: preescolar, primaria, secundaria, técnico y profesional, y universitario). De esta ideología nacionalista se transita a una corriente conductista que establece un modelo tecnológico de currículum, en donde se abandona lo comunitario para centrarse en el individuo y en donde prevalecen los objetivos en lugar de los contenidos y las experiencias. A partir de los años ochenta se genera un cambio en el sistema educativo que se caracteriza por un proceso de descentralización, restructuración curricular y administrativa, y de participación social con énfasis en la interculturalidad y el bilingüismo. La reforma de 1994, acorde con las tendencias internacionales, pone énfasis en la cobertura, la calidad y equidad educativa, la pertinencia y relevancia social. Sostiene que el niño es el constructor de su propio conocimiento y prioriza el desarrollo de aprendizajes significativos orientados a las competencias más que a los contenidos.

$\mathrm{Al}$ iniciar el siglo XXI, la nueva política educativa promovida por Evo Morales se basa en el "vivir bien" respetando el medio ambiente y la vida comunitaria indígena. Considera ideas básicas como la descolonización, la intra e interculturalidad, y la educación productiva y comunitaria; elementos que se presentaron como resistencia ante la influencia de organismos internacionales (UNESCO, BM, BID) y frente a conceptos como calidad educativa y competencias.
Los referentes de la política educatica de Evo Morales hunden sus raíces en los fundamentos de la Escuela-Ayllu de Warisata, que establece un modelo de lucha indígena contra la exclusión, la explotación y el sometimiento, así como una pedagogía socioproductiva (estudio, trabajo y producción) propia del mundo indígena, que involucra una formación holística de los educandos mediante el desarrollo del ser, saber, hacer y decidir, para transformar la realidad

En el tercer capítulo, de Alice Casimiro Lopes y Elizabeth Macedo, "Movimientos recientes en el campo del currículum en el Brasil: articulaciones entre las perspectivas posestructurales y marxistas", las autoras afirman que la hegemonía de las teorías críticas convive y negocia con las perspectivas poscríticas, especialmente con las aportaciones de la literatura norteamericana. Reconocen que desde 1970 los debates en torno al campo del currículum han estado presentes en su país y que es de su interés realizar un análisis de los límites de las relaciones establecidas entre estructura y acción, proyectados a los procesos de cambio social.

Casimiro y Macedo señalan que el campo del currículum en Brasil se constituye entre los años 1950 y 1970, bajo la influencia de la teoría norteamericana, con énfasis en la racionalidad tyleriana y, en algunos casos, se identifican rasgos del cognitivismo de Bruner y Ausubel. Los movimientos políticos en la década de los ochenta, con la vuelta a la democracia, permearon las propuestas curriculares de corte marxista y se incorporaron principios de la nueva sociología de la educación inglesa, con autores como Apple y Giroux, así como autores franceses como Bourdieu y Léfêbvre. Asimismo, se recuperaron los trabajos de Paulo Freire, de la pedagogía históricocrítica (Gramsci) y de algunos pedagogos soviéticos. Posteriormente, con los debates centrados en el contexto cotidiano escolar, y en estudios sobre la diversidad cultural y el multiculturalismo, se realiza un cuestionamiento del discurso de la modernidad, marcado por la hegemonía de una cultura que 
pretende ser universal. En este contexto la teoría curricular intenta ocuparse al mismo tiempo del respeto a la diversidad y del compromiso de la escuela con la promoción de la justicia social

Como una forma disruptiva de acercarse al campo, plantean dos aspectos en la forma de concebir el currículum y la política inherente a su producción desde una perspectiva posestructural; en primer lugar, consideran que existen significaciones en disputa en torno a lo que se concibe como social, se trata por lo tanto de inventar el futuro de la sociedad y decidir por una significación que no esté previamente determinada y de los efectos producidos en el futuro.

En segundo lugar, la construcción de un proyecto curricular, tendría que ser imaginado y construido fuera de los discursos hegemónicos, "en la política, la posibilidad de imaginar y de concebir procesos de significación fuera de los discursos hegemónicos es lo que permite constituir sujetos a partir de esas mismas novedades" (Casimiro y Macedo, 2014: 103)

En el cuarto capítulo, "Evolución del campo del currículum en Colombia (1971-2010)", escrito por Diana Lago de Vergara, Magnolia Aristizábal, María Eugenia Navas Ríos y Nubia Cecilia Agudelo Cely, las autoras indican que en los inicios del siglo $\mathrm{XX}$, los cambios económicos y sociales, producto de la revolución industrial, favorecen la visión de un currículum funcionalista (Bobbit) centrado en la eficiencia y eficacia del sistema educativo y enriquecido por el currículum por objetivos bajo la modalidad de diseño instruccional (Tyler). De manera particular, la teoría curricular anglosajona surgida a mediados del siglo XX es incorporada a su país a través de dos estrategias: la profesionalización (formación de expertos del Ministerio de Educación en los conceptos y prácticas de corte técnico racional) y la creación de instituciones que permitieron aplicar las propuestas curriculares.

En la segunda mitad del siglo XX, el Estado se erige como el diseñador curricular de corte positivista orientado a formar sujetos que pudiesen incorporarse al sector productivo. No obstante, dicha posición fue cuestionada por un sector del magisterio y por grupos de investigadores universitarios.

A partir de la década de los noventa, el Estado orientó su función para velar por la calidad del servicio educativo, por la participación democrática y la autonomía de la institución educativa, así como por la formación integral de un sujeto que sabe ser, convivir y hacer. Asimismo, estableció criterios para evaluar la calidad de la enseñanza, el desempeño profesional del docente y de sus directivos, los logros de los alumnos y la eficacia de los métodos pedagógicos. En 1992, con la creación del Sistema Nacional de Acreditación, se impacta el currículum bajo diferentes características: integralidad, flexibilidad, interdisciplinariedad, metodologías de enseñanza y aprendizaje, formación para la investigación, entre otros.

Cabe señalar que el desarrollo del campo curricular fue acompañado por la producción y publicación de diversos textos tanto institucionales como individuales, producidos por una gran variedad de autores nacionales como extranjeros. Además, con el surgimiento de diferentes programas doctorales en educación, las universidades cobraron mayor relevancia al incorporar como campo disciplinar el del currículum, bajo cuatro líneas de investigación: cultura y educación, comunicación y educación, enseñanza de las ciencias y, currículum y universidad.

En el capítulo quinto, "Hechos sobresalientes del proceso de adopción conceptual y práctico del currículum en el sistema educativo costarricense durante el siglo XX y las dos primeras décadas del siglo XXI", de Rodrigo Campos Hernández y Rafael A. Espinoza Pizarro, los autores señalan que a lo largo de los últimos tres siglos el Estado costarricense ha institucionalizado, desde diversas posturas, la educación como un instrumento que asegure el progreso y desarrollo económico de la nación.

En la segunda mitad del siglo XIX se inicia la Reforma Educativa, de marcada influencia liberal, bajo los principios de uniformidad, obligatoriedad, 
gratuidad y laicidad. A partir de 1900 aparece en el discurso educativo el concepto de plan de estudios (equivalente al de currículum) que comprende un conjunto de materias, disciplinas o asignaturas que un sujeto cognoscente debe atender para que responda a determinados fines y visiones del sistema educativo. En 1971 el Ministerio de Educación se erige como el diseñador curricular por excelencia y mantiene un enfoque técnico instrumental racionalista del currículum, además tiene la facultad de promover o vetar, evaluar y certificar cualquier innovación curricular; en 1973 aparece el concepto de currículum entendido como el conjunto de experiencias que el educando adquiere a través de su educación formal, así como las vividas en el medio extraescolar, que conducen al educando en su formación para la vida dentro de una sociedad cambiante. En la década de los ochenta, en materia curricular, se impulsa el constructivismo y se enfatiza en seis aspectos: los valores, la educación para la vivencia democrática, la educación ecológica, científica y tecnológica, las oportunidades educativas y culturales, la eficiencia y racionalización de los recursos. En la primera década de este siglo se establece un modelo curricular que fortalece la calidad y pertinencia de la educación, encaminado a crear en el educando las capacidades humanas que le permitan integrarse a la economía global a base de productividad, ingenio, conocimiento y destreza. De esta manera, el Estado ha institucionalizado la educación como un instrumento que asegura el progreso y desarrollo económico de la nación.

En el capítulo sexto, "El campo curricular y su expresión en las reformas curriculares en Chile", de Abraham Magendzo, Mirtha Abraham y Sonia Lavín, los autores afirman que toda construcción curricular implica una postura epistemológica, ideológica y política. En sus orígenes, se asoció el concepto de currículum con el de plan de estudios y fue con la creación de la Asociación Chilena del Currículum Educacional que se abrió un espacio de debates sobre la educación y la democracia, una de sus mayores aportaciones fue el modelo de educación centrado en la persona.

Asimismo, señalan que las formulaciones curriculares a partir de los sesenta se sustentan en la corriente positivista que involucra una escisión entre el sujeto y el objeto, con gran énfasis en la redacción de objetivos, la secuenciación y ordenamiento de contenidos, y en la verificación y comprobación de sus resultados. A fines de esa década, los análisis curriculares fueron realizados bajo la perspectiva crítica (reconceptualista), en donde la realidad es concebida como una producción social compleja y contradictoria construida por los sujetos. Cabe subrayar que durante el periodo de la Unidad Popular (1970-1973) se presentaron propuestas que no lograron cristalizar en cambios curriculares de la educación preescolar, básica y media, ya que fueron truncados por el golpe militar de 1973. A fines de los ochenta, se asume el enfoque del currículum como praxis, que rescata los aspectos relevantes del quehacer escolar, el papel del profesor en el diseño y desarrollo curricular, y centrar el estudio del currículum en la relación entre el proyecto y la acción. A partir de la reforma de los noventa se aprecia una postura ecléctica que involucra desde una concepción curricular racionaltecnológica-académica, un currículum de colección, un currículum de base conductista, un currículum reconstructivista, hasta un currículum de perspectiva crítica; sin embargo, a partir de los objetivos fundamentales transversales incorporados al marco curricular de la reforma, se promueve una actitud de participación y sentido comunitario, objetivos que intentan desarrollar la dimensión intelectualcognoscitiva y una formación ética relacionada con la democracia y la ciudadanía.

En el capítulo séptimo, "Constitución del campo curricular en la República Dominicana”, de Minerva Vincent, la autora señala que a lo largo de los siglos XIX y XX, el concepto de educación en República Dominicana ha sufrido diversas transformaciones. 
En la primera mitad del siglo XIX, la educación estaba orientada al contenido libresco y memorístico. Para la segunda mitad del siglo (1878), el pensamiento positivista racionalista de Eugenio María de Hostos permitió concebir al currículum como una disciplina.

Durante la década de los sesenta y setenta del siglo XX, se garantizó la libertad de enseñanza y se proclamó la ciencia como fundamento básico de la educación. Sin embargo, el golpe militar trajo consigo el retorno a la educación memorística sin ningún tipo de reflexión. Por otra parte, con la reforma a la educación media se estableció un modelo educativo técnico racional orientado a la formación y calificación de recursos humanos para las empresas. Con la misma orientación, en 1977 se reforma la educación primaria y el concepto de currículum fue concebido como sinónimo de plan de estudios, con una orientación conductista.

El currículum, como objeto de estudio, tuvo lugar en 1982 con el primer programa de maestría en Educación Superior; este programa contempló la relación del currículum con las estructuras sociales, los tipos de diseños curriculares, sus componentes, así como con los fundamentos y estrategias de evaluación. Desde las didácticas se trabajaron temas relacionados con la planificación y métodos de enseñanza, formando parte de su cuerpo docente Raquel Glazman, Alfredo Furlán, Adriana Puiggrós, entre otros. Con el Plan Decenal de Educación 19932002, apoyado por organismos internacionales (BID, BM, PNUD) e influido por la reforma educativa en España, se asumió una interpretación constructivista del aprendizaje; su propuesta curricular fue concebida como estrategia para la formación de sujetos democráticos y transformadores de la realidad material, social y cultural.

En el capítulo octavo, "La conformación del campo curricular en México", de Ángel Díaz Barriga y José María García Garduño, los autores señalan que la conformación del campo del currículum en
México ha sido ampliamente estudiada desde principios de la década de los ochenta. Hacen énfasis en el papel que han jugado los estados de conocimiento sobre el campo, elaborados por investigadores de diversas instituciones de educación superior, en el marco del Consejo Mexicano de Investigación Educativa (COMIE), para dar cuenta de los debates y conflictos en el campo. Díaz Barriga plantea que el surgimiento del campo obedeció a situaciones coyunturales y a la expansión de la pedagogía industrial gestada en los Estados Unidos, así como a su adecuación para la educación mexicana, situación que fue objeto de diversas críticas, así como de la generación de propuestas alternativas, en un primer momento, hasta su revisión a la luz de una teoría crítica aplicada al campo del currículum.

Díaz Barriga y García afirman que el ingreso de México al campo del currículum estuvo ligado a movimientos sociales, como el del 68, y al aumento de la matrícula estudiantil. Asimismo, advierten diversas etapas en la conformación del campo, la primera estuvo ligada al diseño curricular bajo un enfoque racional, ligado a la tecnología educativa; la segunda se caracterizó por una búsqueda de alternativas cercanas a la realidad mexicana, y la tercera por la construcción desde la teoría crítica aplicada al campo del currículum.

Los autores identifican que el movimiento de apertura democrática generado por el movimiento estudiantil del 68 , trajo consigo una serie de reformas en todos los niveles educativos, así como la creación de propuestas alternas centradas en el aprendizaje del estudiante y en su formación crítica de la realidad social, además de un cuestionamiento tanto a la estructuración y organización curricular, basados en la fragmentación del conocimiento y como en las estructuras académico-administrativas rígidas y anquilosadas. Entre las propuestas significativas se encuentran: el Plan de autogobierno de arquitectura de la UNAM, el Programa de Medicina General Integral de la Facultad de Medicina de la 
UNAM; el Currículum Modular por objetos de trasformación de la Universidad Autónoma Metropolitana, y la Reforma Académica de la Universidad Iberoamericana.

En el apartado "El ascenso y florecimiento de la corriente crítica del currículum", expresan que esta propuesta arribó a México a finales de la década de los setenta y principios de los ochenta, por la construcción de jóvenes curricularistas, provenientes tanto del país como de Argentina, e identifican como sus artífices a: Ángel Díaz Barriga, Alicia de Alba, Patricia Aristi, Alfredo Furlán, Azucena Rodríguez, Eduardo Remedí y Roberto Follari. A diferencia del pensamiento sajón encabezado por Kliebard, en América Latina se debatía a partir de los desarrollos de Paulo Freire, de la Escuela Francesa como la sociología institucional y de la Escuela de Frankfurt. Este periodo se caracterizó por la generación de una producción académica importante a través de artículos, libros, y congresos.

En el apartado "El posmodernismo y posestructuralismo", los autores afirman que este movimiento se empezó a gestar a mediados de los ochenta, saliendo a la luz en los inicios de la década de los noventa, e identifican como autora principal a Alicia de Alba, quien ha sido la más importante pieza en la conformación y desarrollo de este movimiento curricular al encaminar su lucha contra la construcción discursiva que había encerrado el currículum en los últimos años, a través de su obra Currículum: crisis, mito y perspectiva (1995).

En el siguiente apartado, "La internacionalización y cosmopotización del currículum", resaltan la importancia del intercambio, diálogo y de las visitas recíprocas y publicaciones conjuntas entre curricularistas mexicanos, europeos y estadounidenses, con miras a la configuración de nuevos espacios sociales y culturales a nivel mundial, en la que los autores citados previamente han incursionado ampliamente, ocupando un lugar estratégico para el desarrollo de estos procesos la fundación de la International
Association for the Advancement of Curriculum Studies (IAACS), en 2001.

En el último apartado, referido a la institucionalización del campo, los autores señalan que a pesar de su desarrollo en México aún no existen programas de posgrado orientados a la formación de curriculistas y los debates se han concentrado primordialmente en la educación superior, específicamente en la UNAM.

En el capítulo noveno, "El currículo en Venezuela: del eficientismo social de Ralph Tyler a la postmodernidad (1970-1997)", de José Pascual Mora García, el autor señala que a partir de 1936 se diseñó en Venezuela un plan de formación de maestros bajo la teoría curricular norteamericana de John Dewey, que se complementó con la Reforma Curricular de Educación de 1940 y con los postulados de la Escuela Nueva y la pedagogía experimental.

La década de los cuarenta se caracterizó por el debate entre el Ministerio de Educación y el modelo educativo de Luis Beltrán Prieto. El primero está vinculado con criterios de calidad y el segundo con la educación de masas, fundada en el Humanismo Democrático, que contemplaba la participación del niño como ser activo y responsable en la vida de la escuela, y la incorporación de la escuela en las nuevas formas sociales de trabajo. La mayor aportación de Prieto fue la consolidación de la teoría del currículum centrada en el niño y el adolescente.

En 1970 se asume el paradigma eficientista (Tyler y Bloom); los objetivos del currículum se plantean en términos de conductas observables, desarrollo de pruebas y criterios referenciales, así como en conceptos del campo de la administración y la teoría de las organizaciones. Por su parte, el movimiento de renovación universitaria desarrolla un plan de resistencia fundamentado en la Teoría Crítica y la Teoría de la Liberación, principalmente. En 1985 se presenta el Normativo de Educación Básica, en el que la teoría del currículum es abordada a partir de fundamentos psicológicos con aportes del conductismo, cognitivismo, humanismo y constructivismo. 
La década de los noventa se caracterizó por un proceso de reflexión en el campo intelectual de la educación y pedagogía orientado a promover la calidad educativa. La teoría general de sistemas y la teoría de la comunicación fueron incorporadas epistemológicamente por la visión tecnológica del currículum, en tanto que el rol del docente investigador surgió a partir del modelo de investigación integrativa adaptativa. En esta década, el pensamiento curricular se trabajó a partir de tres tendencias: el diseño curricular enfocado en la didáctica general, en las didácticas especiales y centrado en las disciplinas. A partir de 1992, la teoría del currículum postmoderno se constituyó como una línea de investigación, reconocida en el Currículum Básico Nacional (1997), que considera a la escuela como órgano social para adecuarse a las exigencias de la sociedad posmoderna y colaborar con la familia y la comunidad.

En el capítulo décimo, "Un estudio de los procesos de apropiación y desarrollos específicos en los países de la región (Uruguay)", de Rosalía Barcos y Silvia Trías, las autoras indican que el currículum, como praxis, se remonta a principios del siglo XX con la conformación del sistema educativo nacional bajo un enfoque positivista: la educación debía ser científica y transmitir el saber acumulado por la ciencia, mientras que en lo filosófico, la enseñanza debía ser laica. Sin embargo, el currículum como campo de estudio es de tardía aparición en Uruguay. Antes de la década de los noventa, la investigación sobre el currículum y la teoría curricular era escasa: en el plan de estudios para la formación de profesores aparecía la asignatura de didáctica y algunas didácticas especiales, pero no el concepto de currículum.

En la década de los noventa, los docentes participaron en la elaboración de documentos curriculares para la educación primaria que, bajo una perspectiva del cognitivismo, articulan nuevas miradas sobre cómo aprenden los sujetos. Por su parte, la educación media se centró, a partir del Plan 96, en el paradigma de la cognición por medio de autores como Vigotsky, Brunner, Díaz-Barriga Arceo, Carretero, entre otros. A principios del año 2000, mediante un trabajo interdisciplinario (sociólogos, curriculistas, docentes de didáctica), se elaboraron y publicaron documentos curriculares, investigaciones y se le dio seguimiento a las innovaciones. Esta producción académica y de investigación ha permitido abrir líneas de investigación teóricas, empíricas e históricas, pero aún es limitada.

En el último capítulo, "Desarrollo del currículum en América Latina. Lo que hemos aprendido" escrito por Ángel Díaz Barriga y José María García Garduño como una especie de conclusión, los autores señalan que si bien en América Latina se han incrementado las revistas de investigación educativa y que la realidad curricular ha permitido una apropiación y construcción de categorías y conceptos orientadores de la práctica educativa, el currículum; en la región, representa un área a explorar a partir de diferentes rutas conceptuales que favorezcan el desarrollo del campo del currículum: el campo curricular muestra signos de hibridismo, mestizaje, internacionalización y perspectiva cosmopolita.

\section{Cómo citar este artículo:}

Barrón-Tirado, María-Concepción (2021), “Reseña del libro coordinado por Ángel Díaz Barriga y José María García Garduño, Desarrollo del currículum en América Latina. Experiencia de diez países", Revista Iberoamericana de Educación Superior (RIES), vol. XII, núm. 33, pp. 214-221, DOI: https://doi.org/10.22201/iisue.20072872e.2021.33.866 [Consulta: fecha de última consulta]. 